\title{
QUEEN'S
UNIVERSITY
BELFAST
}

\section{Exploring the Design Flexibility of the Class-E Power Amplifier with Shunt Capacitance and Shunt Filter}

Safari Mugisho, M., Thian, M., Grebennikov, A., Makarov, D., \& Krizhanovski, V. (2019). Exploring the Design Flexibility of the Class-E Power Amplifier with Shunt Capacitance and Shunt Filter. In 2019 IEEE Radio and Wireless Symposium (RWS) Institute of Electrical and Electronics Engineers Inc..

https://doi.org/10.1109/RWS.2019.8714425

Published in:

2019 IEEE Radio and Wireless Symposium (RWS)

Document Version:

Peer reviewed version

Queen's University Belfast - Research Portal:

Link to publication record in Queen's University Belfast Research Portal

Publisher rights

(c) 2018 IEEE.

This work is made available online in accordance with the publisher's policies. Please refer to any applicable terms of use of the publisher.

\section{General rights}

Copyright for the publications made accessible via the Queen's University Belfast Research Portal is retained by the author(s) and / or other copyright owners and it is a condition of accessing these publications that users recognise and abide by the legal requirements associated with these rights.

Take down policy

The Research Portal is Queen's institutional repository that provides access to Queen's research output. Every effort has been made to ensure that content in the Research Portal does not infringe any person's rights, or applicable UK laws. If you discover content in the Research Portal that you believe breaches copyright or violates any law, please contact openaccess@qub.ac.uk. 


\title{
Exploring the Design Flexibility of the Class-E Power Amplifier with Shunt Capacitance and Shunt Filter
}

\author{
Moïse Safari Mugisho ${ }^{1}$, Mury Thian ${ }^{1}$, Andrei Grebennikov ${ }^{2}$, \\ Denis G. Makarov ${ }^{3}$, and Vladimir G. Krizhanovski ${ }^{3}$ \\ ${ }^{1}$ Queen's University Belfast, Northern Ireland, ${ }^{2}$ Sumitomo Electric Europe, United Kingdom, \\ ${ }^{3}$ Vasyl'Stus Donetsk National University, Ukraine
}

\begin{abstract}
The Class-E power amplifier (PA) with shunt capacitance and shunt filter offers a unique design flexibility which can be exploited either to extend the maximum operating frequency of the PA or to allow the use of large active devices with high power handling capability. In this paper, a novel transmission-line load network is proposed to provide the drain of the active device with the required load impedances at the fundamental frequency as well as at even and odd harmonic frequencies. The concept is verified through simulations and measurements of a circuit prototype, which delivers a peak drain efficiency of $90.2 \%$, a peak power-added efficiency of $82.7 \%$, and a peak output power of $39.8 \mathrm{dBm}$ at 1.37 GHz.
\end{abstract}

Index Terms - Class E, GaN, harmonic tuning, high efficiency, maximum operating frequency, power amplifier, shunt filter, switching amplifier, transmission line.

\section{INTRODUCTION}

The Class-E power amplifier (PA) with shunt capacitance and series filter, first introduced by the Sokals [1], has been widely used due to its simple topology and high-efficiency operation. However, the maximum operating frequency $\left(f_{\max }\right)$ of this PA is strictly constrained by the transistor output capacitance, and its circuit bandwidth is dictated by the required loaded quality factor. To resolve this problem, several modified topologies have been proposed [2]-[4], including the recent high-efficiency Class-E PA with shunt capacitance and shunt filter shown in Fig. 1(a) [5]-[6]. Unlike the classical Class E, the newly introduced topology inherently incorporates in its load network a series $L$, which can be used to absorb the transistor output inductance and parasitic lead inductance. In [5], the solution to the system of equations describing the PA was provided for a specific value of $q$ that is 1.6 , where $q$ is described by (1).

$$
q=\frac{1}{\omega \sqrt{L C}}
$$

The analysis presented in [6] resulted in a set of solutions for $q<1.6, q=1.6$ and $q>1.6$, showing that there is a dependency of the load network parameters on $q$ such that for values of $q<1.6$, the series reactance $(X)$ is capacitive, for values of $q>1.6, X$ is inductive, and for $q=1.6, X$ is zero. Thus, the analysis presented in [5] represents a special case of the analysis in [6].

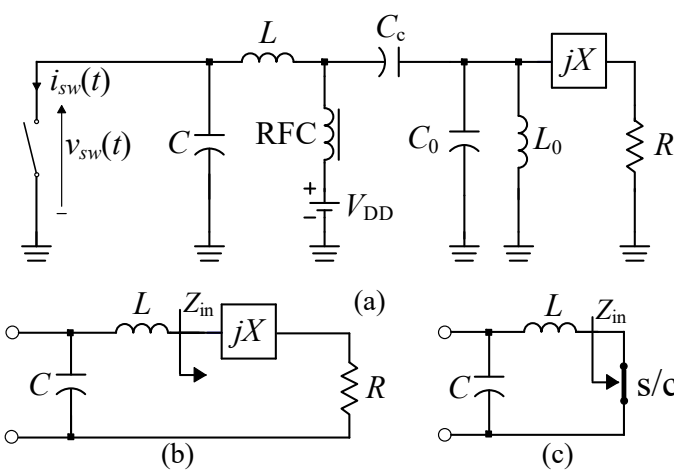

Fig. 1. The Class-E PA with shunt capacitance and shunt filter: (a) basic circuit, (b) equivalent load network at the fundamental frequency, (c) equivalent load network at harmonic frequencies.

In [5], it was shown that the $f_{\max }$ of a Class-E PA with shunt capacitance and shunt filter for a prescribed output power $\left(P_{\text {out }}\right)$ and DC supply voltage $\left(V_{\mathrm{DD}}\right)$ is strictly constrained by the transistor output capacitance $\left(C_{\text {out }}\right)$, and for $q=1.6$, it is 1.91 times higher than $f_{\max }$ of the Class-E PA with shunt capacitance and series filter.

In this paper, the results obtained in [5]-[6] are used to show that the dependency of the load network parameters on $q$ can be exploited to further extend $f_{\max }$ of the Class-E PA with shunt capacitance and shunt filter for a given $C_{\text {out }}$. Specifically, it will be shown that by exploiting the dependency of the load network parameters on $q, f_{\max }$ can be extended above 1.91 times higher than that of a Class-E with shunt capacitance and series filter. Another way to exploit this dependency would be to design a PA using an active device with a higher value of $C_{\text {out }}$, which results in a higher $P_{\text {out }}$ for a given $f_{\max }$. To further highlight the unique design flexibility of the Class-E PA with shunt capacitance and shunt filter, we built and tested a circuit prototype using a commercially available $\mathrm{GaN}$ device operating in the Lband.

It should be noted that the load network proposed for the special case presented in [5] can only practically match purely resistive impedances. However, for the general case presented in [6], the optimum load impedance is a complex value. A novel transmission-line load network that fulfils the operational conditions of the Class-E PA with shunt 
capacitance and shunt filter for the general case is proposed and analyzed in this paper.

\section{IDEALIZEd Operation ANd FIguRES OF MERIT}

The load network of the Class-E PA with shunt capacitance and shunt filter, depicted in Fig. 1(a), consists of a shunt capacitance $(C)$, a series inductor $(L)$, a shunt parallel resonant circuit $\left(L_{0} C_{0}\right)$, a series reactance $(X)$, a $\mathrm{RF}$ choke (RFC), and a DC blocking capacitor $\left(C_{\mathrm{c}}\right)$. Tuned at fundamental frequency $\left(f_{0}\right)$, the $L_{0} C_{0}$ circuit provides an open circuit at $f_{0}$ and short circuit terminations at harmonic frequencies. As a result, the PA load network at $f_{0}$ and $\mathrm{n} \times f_{0}$ reduces to that shown in Figs. 1(b) and (c), respectively.

The dependency of $\omega L$ and $X$ on $q$ is illustrated in Fig. 2(a), showing that for $q=1.6, X=0$, resulting in the circuit in [5]. As $q$ decreases below 1.6, the value of $\omega L$ increases while $X$ now becomes capacitive. As $q$ increases above 1.6, the value of $\omega L$ decreases and $X$ becomes inductive thus compensating for the decrease in $\omega L$.

More importantly, the dependency of $\omega C$ on $q$ as depicted in Fig. 2(b) shows that as $q$ increases, the value of $\omega C$ increases, meaning that for a specific value of $C$ representing the intrinsic device output capacitance $\left(\mathrm{C}=\mathrm{C}_{\text {out }}\right), f_{\max }$ increases with the increasing $q$. Thus, the $f_{\max }$ of the Class-E PA with shunt capacitance and shunt filter can be expressed as in (2), where the dependency of $k$ on $q$ is shown in Fig. 2(b), from which it can be seen that for $q=$ $1.6, k=0.097$, that is identical to (32) in [5], and 1.91 times higher than that in [1]. It is worth noting for $q=1.97, k=$ 0.227 , yielding $f_{\max }$ being 4.476 times higher than that in [1].

$$
f_{\max }=k \frac{P_{\text {out }}}{V_{\mathrm{DD}^{2}} C_{\text {out }}}
$$

The dependency shown in Fig. 2(b) also means that for a fixed value of $f_{\max }$, the value of $C$ increases for increasing $q$, hence allowing the use of active devices with higher output capacitance and higher output power capability. However, it should be noted that $R$ decreases as $q$ increases. Consequently, the selection of $q$ is limited by the acceptable level of impedance matching loss introduced by lower values of $R$.

\section{PROPOSED PA WITH TL LOAD NETWORK}

To verify the theory described in Section II, a PA prototype was designed with the following specifications: $V_{\mathrm{DD}}=28 \mathrm{~V}$ and $P_{\text {out }}=10 \mathrm{~W}$. The Cree CGH40010F GaN HEMT with $C_{\text {out }}=1.3 \mathrm{pF}$ and $L_{\text {out }}=0.653 \mathrm{nH}$ was used in the design. The value of $q=1.85$ was selected to give $C=1.272 \mathrm{pF} \approx C_{\text {out }}$ and $f_{\max }=1.5 \mathrm{GHz}$ (see Fig. 2(b)) resulting in $k=0.1496$ which is 2.9 higher than that in [1] and 1.54 higher than that in [5].
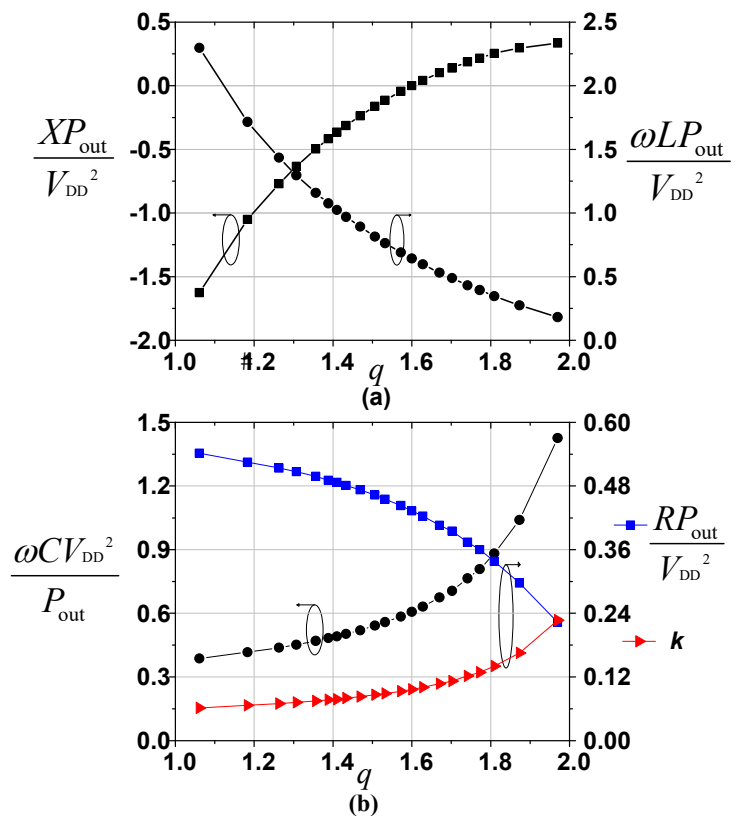

Fig. 2. Normalized load network parameters of the Class-E PA with shunt capacitance and shunt filter.

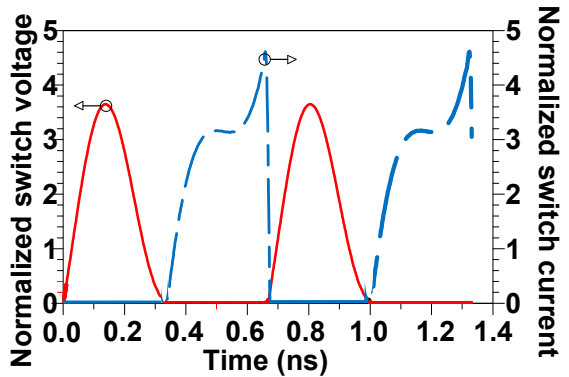

Fig. 3. Simulated switch voltage and current waveforms using an ideal switch model with the switch voltage normalized to $V_{\mathrm{DD}}$ and the switch current normalized to $I_{\mathrm{DD}}$.

The value of $L=2.662 \mathrm{nH}$ is extracted from Fig. 2(a) for $q=1.85$ and $f=1.5 \mathrm{GHz}$. For the given $V_{\mathrm{DD}}$ and $P_{\text {out }}$ values, $X=20.4 \Omega$ and $R=25.1 \Omega$, determined from Figs. 2(a) and (b), respectively. The circuit was first simulated using an ideal switch model, resulting in the normalised switch voltage and current waveforms in Fig. 3, where the peak switch voltage of $3.65 \times V_{\mathrm{DD}}$ and the peak switch current of $4.6 \times I_{\mathrm{DD}}$ show a good agreement with the theoretical prediction in [6].

The proposed PA with transmission-line (TL) load network is depicted in Fig. 4, where $C_{\mathrm{c}}$ is a DC blocking capacitor and $C_{\mathrm{b}}$ is a bypass capacitor. The excess inductor $L_{\mathrm{e}}=L-L_{\text {out }}=(2.662-0.653) \mathrm{nH}$ is realized using a series transmission line $\left(\mathrm{TL}_{1}\right)$ with a characteristic impedance of $Z_{1}$ and electrical length of $\theta_{1}$, whose value is determined using (3). For $\theta_{1}$ to be considered sufficiently short at $f_{0}$, the value of $Z_{1}$ should be selected to satisfy the relationship in (3). 


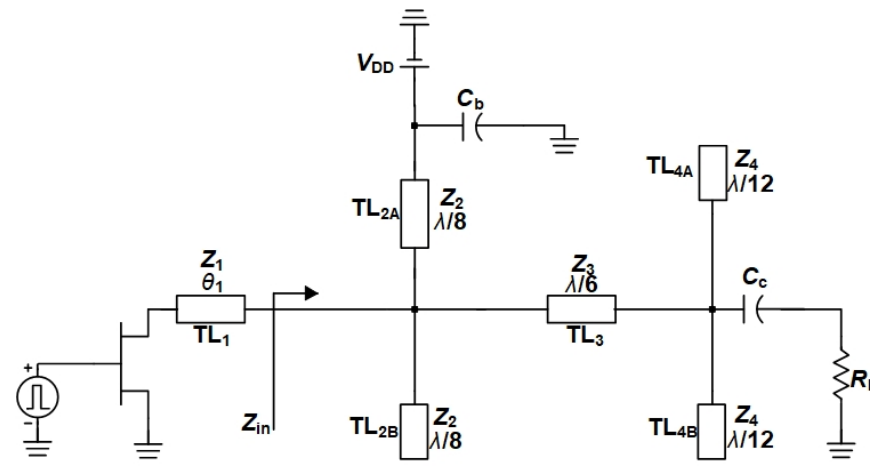

Fig. 4. Proposed PA with novel TL load network.

$$
\theta_{1}=\tan ^{-1}\left(\frac{\omega_{0} L_{\mathrm{e}}}{Z_{1}}\right) \text { with } Z_{1}>\frac{4 \omega_{0} L_{\mathrm{e}}}{\pi}
$$

A shorted $\lambda / 8$ stub $\left(\mathrm{TL}_{2 \mathrm{~A}}\right)$ in conjunction with an opencircuited $\lambda / 8\left(\mathrm{TL}_{2 \mathrm{~B}}\right)$ enforce short-circuit terminations at even harmonic frequencies, and open-circuit terminations at fundamental and odd harmonic frequencies, with $Z_{2}$ set to a high value [3]. A series $\lambda / 6$ transmission line $\left(\mathrm{TL}_{3}\right)$ together with two open-circuited $\lambda / 12$ stubs (TL4A and TL4B), enforce a short-circuit termination at $3 f_{0}$. Hence, $Z_{\text {in }}=0 \Omega$ at $2 n f_{0}$ and $3 f_{0}$, satisfying the load impedance requirement in Fig. 1(c). The characteristic impedances of $\mathrm{TL}_{3}$ and $\mathrm{TL}_{4 \mathrm{~A}} / \mathrm{TL}_{4 \mathrm{~B}}$, i.e. $Z_{3}$ and $Z_{4}$, respectively, are calculated to match the optimum load impedance $Z_{\mathrm{opt}}=(R+j X) \Omega=$ $(25.1+j 20.4) \Omega$ to the standard $50 \Omega$ load resistance $\left(R_{\mathrm{L}}\right)$, thus satisfying the load impedance requirement in Fig. 1(b). At $f_{0}$, the input impedance $Z_{\text {in }}$ is given by

$$
Z_{\text {in }}=Z_{3}\left[\frac{3 Z_{3} Z_{4}+j \sqrt{3}\left(2 Z_{3}-Z_{4}\right) R_{\mathrm{L}}}{\left(2 Z_{3}+3 Z_{4}\right) R_{\mathrm{L}}-j \sqrt{3} Z_{3} Z_{4}}\right]
$$

For $R_{\mathrm{L}}$ to be matched to $Z_{\text {opt }}$ at $f_{0}$, the $\operatorname{Re}\left\{Z_{\text {in }}\right\}=R$ and the $\operatorname{Im}\left\{Z_{\text {in }}\right\}=X$, resulting in a system of two equations (5)-(6) which can be solved for the two unknowns parameters $Z_{3}$ and $Z_{4}$.

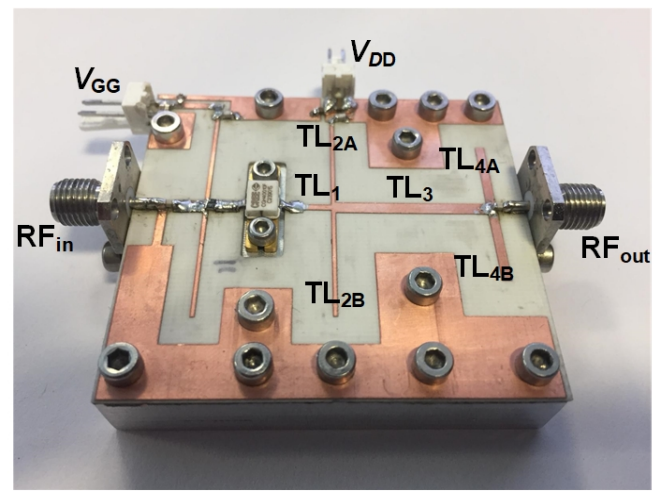

Fig. 5. The constructed transmission-line Class-E PA with shunt capacitance and shunt filter.

$$
\begin{aligned}
3 Z_{3}{ }^{2} Z 4^{2}(4 & R \mathrm{~L}-R)-R \mathrm{~L}^{2} R\left(2 Z_{3}+3 Z_{4}\right)^{2}=0 \\
& 3 Z_{3}^{2} Z 4^{2}\left(\sqrt{3} Z_{3}-X\right)+R \mathrm{~L}^{2}\left(2 Z_{3}+3 Z_{4}\right) \\
& {\left[\sqrt{3} Z_{3}\left(2 Z_{3}-Z_{4}\right)-X\left(2 Z_{3}+3 Z_{4}\right)\right]=0 }
\end{aligned}
$$

\section{IMPLEMENTATION AND MEASUREMENTS}

The designed PA was constructed on a $0.51 \mathrm{~mm}$ thick Rogers RO4003C substrate with a dielectric constant of 3.38 and a loss tangent of 0.0027 and is shown in Fig. 5. A continuous-wave signal was applied to the PA using a Rohde \& Schwarz SMAB100A signal generator, and the output power was measured by a Keysight N9320A spectrum analyzer.

The measured PA performance, depicted in Fig. 6, shows that, when biased with a gate voltage $V_{\mathrm{GG}}=-2.7 \mathrm{~V}$ and a drain voltage $V_{\mathrm{DD}}=28 \mathrm{~V}$, the PA delivers a peak drain efficiency $(D E)$ of $90.2 \%$, a peak power added efficiency (PAE) of $82.7 \%$, a peak $P_{\text {out }}$ of $39.8 \mathrm{dBm}$, and a smallsignal gain of $14 \mathrm{~dB}$ at an operating frequency of $1.37 \mathrm{GHz}$.

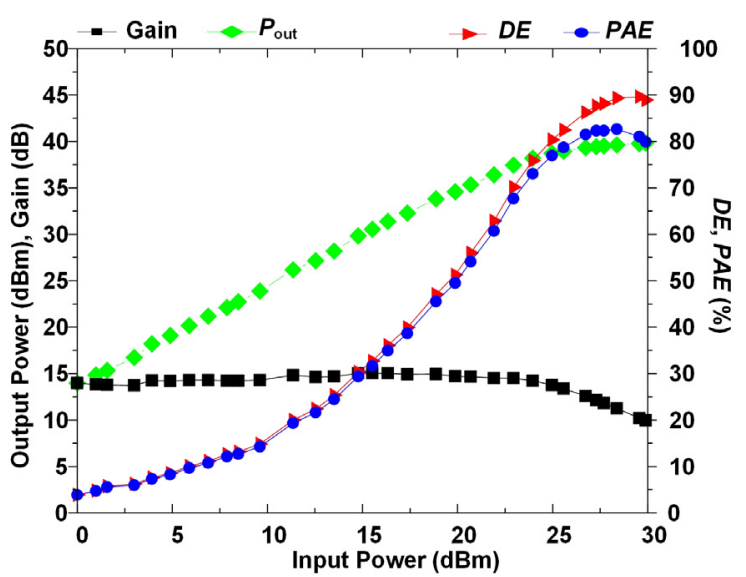

Fig. 6. Measured PA performance versus input power at $1.37 \mathrm{GHz}$ with $V_{\mathrm{DD}}=28 \mathrm{~V}$ and $V_{\mathrm{GG}}=-2.7 \mathrm{~V}$.

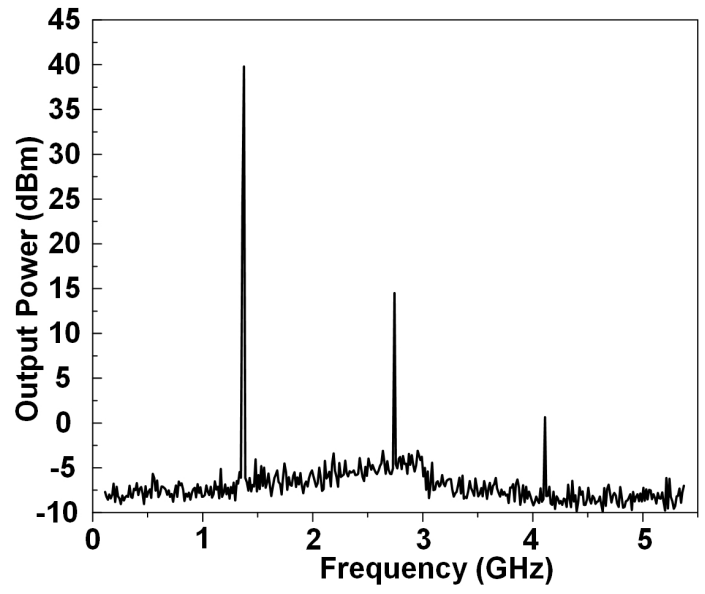

Fig. 7. Measured output power spectrum at $V_{\mathrm{DD}}=28 \mathrm{~V}$ and $V_{\mathrm{GG}}=-2.7 \mathrm{~V}$. 
The values of $P_{\text {out }}$ and power gain at the peak $P A E$ are $39.6 \mathrm{dBm}$ and $11.2 \mathrm{~dB}$, respectively. Fig. 7 shows the measured output power spectrum with excellent second and third harmonic suppression levels of $25 \mathrm{dBc}$ and $39.7 \mathrm{dBc}$, respectively, showing the effectiveness of the proposed transmission-line load network.

\section{CONCLUSION}

The design flexibility offered by the Class-E PA with shunt capacitance and shunt filter has been demonstrated and exploited to operate the PA at higher operating frequencies. A novel transmission-line load network that satisfies the required PA load impedances at the fundamental as well as harmonic frequencies has been proposed.

\section{ACKNOWLEDGMENT}

This work was supported by the UK EPSRC under grant no. EP/P013031/1. The authors would like to thank Wolfspeed for providing the GaN power device.

\section{REFERENCES}

[1] N. O. Sokal and A. D. Sokal, "Class E - a new class of high-efficiency tuned single ended switching power amplifiers," IEEE J. Solid-State Circuits, vol. 10, no. 3, pp. 168-176, Jun 1975.

[2] M. Thian and V. Fusco, "Transmission-line Class-E power amplifier with extended maximum operating frequency," IEEE Trans. Circuits Syst. II, Exp. Briefs, vol. 58, no. 4, pp. 195-199, Apr. 2011.

[3] M. Thian, A. Barakat, and V. Fusco, "High-efficiency harmonicpeaking Class-EF power amplifiers with enhanced maximum operating frequency," IEEE Trans. Microw. Theory Techn., vol. 63, no 2, pp. 659-671, Feb. 2015.

[4] M. Thian and V. Fusco, "Idealized operation of zero-voltageswitching series-L/parallel-tuned Class-E power amplifier," IET Circuits Devices Syst., vol. 2, no. 3, pp. 337-346, Jun. 2008.

[5] A. Grebennikov, "High-efficiency Class-E power amplifier with shunt capacitance and shunt filter," IEEE Trans. Circuits Syst. I, Reg. Papers, vol. 63, pp. 12-22, Jan. 2016.

[6] M. S. Mugisho, D. G. Makarov, Y. V. Rassokhina, V. G. Krizhanovski, A. Grebennikov, and M. Thian, "Generalized analysis and design of high-efficiency Class-E power amplifier with shunt capacitance, and shunt filter," unpublished. 